\title{
Algorithms of Cause-and-effect Approach to Increase Service Net Efficiency
}

\author{
Alexey Anatolievitch Bezrodny ${ }^{1}$, Anatoliy Mikchailovitch Korolenok ${ }^{1}$, \\ Aleksandr Fedorovitch Rezchikov ${ }^{2}$ \\ ${ }^{1}$ Faculty of Design, Construction and Exploitation of Pipeline Transport Systems, Gubkin University, Moscow, Russia \\ ${ }^{2}$ Institute of Control Sciences Named After V.A. Trapeznikov, Moscow, Russia
}

Email address:

BezrodnyAA@yandex.ru (A. A. Bezrodny), korolynok.a@gubkin.ru (A. M. Korolenok), rw4cy@mail.ru (A. F. Rezchikov)

\section{To cite this article:}

Alexey Anatolievitch Bezrodny, Anatoliy Mikchailovitch Korolenok, Aleksandr Fedorovitch Rezchikov. Algorithms of Cause-and-effect Approach to Increase Service Net Efficiency. Engineering and Applied Sciences. Vol. 5, No. 2, 2020, pp. 34-40.

doi: $10.11648 /$ j.eas.20200502.11

Received: July 22, 2019; Accepted: August 29, 2019; Published: March 23, 2020

\begin{abstract}
Service nets distribute goods and services that is why their improvement is one of the important tasks of any production chain. There is many models related to the sphere however, in many of them it is possible to see some weaknesses. At the same time since the task mentioned is complicated and large scaled some systematical approach should be applied that needs to be modified taking into consideration presence in the systems objects, processes, events and phenomena of various nature and origin. As possible approach one consideres so called cause-and-effect one that provides a universal description of complex systems and possibility of descision making in undefined or under-defined situations. In the artcile below this approach is considered and informational logic diagrams and algorithms to increase service net efficiency are presented. Gas stations were taken as examples and sphere of practical application, that results are discussed.
\end{abstract}

Keywords: Algorithm, Complex System, Service Net, Causal-and-effect, Petroleum

\section{Introduction}

Service nets are important parts of present economy [1]. The statement is true for petroleum supply also [2, 3] that may be considered as a good example. To develop it there should be improvements of the existing models and optimization methods [4-6] to make management and control more efficient considering last as one of the main tasks of the present century [7].

A Service net (company, structure, etc.) as any complex system works under requirements of the upper, goal-orienting and parents systems, follows demands of consumers, takes into consideration possibilities of competitors and suppliers, fulfills laws, makes innovations and so on. These demands, influences and restrictions (further-factors) on/to/from a system and its surroundings may be formalized as elements of mathematical sets that permit to create in a parameter/factor space some feasible regions, goal areas and so on.

Under the process approach if one considers gas stations as an example of service nets it is usually determined the station themselves (that serve consumers), station complexes or gas station nets (that provide work of the stations in a region) and companies as legal entities.

The investigation object is a large scale complex territorially distributed hierarchical human-machine system [8] tasks to increase efficiency of which are the ones of many criteria optimization [9]. Existing models and methods to resolve modern practical tasks are frequently not enough since they are not systemized. In addition, there are mainly considered state-level or object-level structures without due attention to regional service nets (station complexes), transportation (clients) flows are modeled as simplistic that is non-adequate, modern petroleum equipment like OPT (Outdoor Payment Terminal) and so on is not considered, etc.

The task is to bring efficiency or key performance indicator (KPI) $\mathrm{K}$ to its maximum at given and perspective factors of the system and surroundings $G$ during $\Delta t$ by developing structures $\mathrm{S}=\langle\mathrm{X}, \mathrm{U}, \mathrm{GR}\rangle$ and choosing control actions, $\langle\mathrm{C}, \mathrm{A}, \mathrm{X}, \mathrm{U}, \mathrm{R}\rangle$ that is 


$$
K(S,\langle C, A, X, U, R\rangle, \Delta t, G) \rightarrow \max
$$

where $\mathrm{X}$ - set of control means, $\mathrm{U}$ - relation between them, GR - structure graphs, C - control functions, A - control algorithms, $\mathrm{R}$ - variant of a control structure. In given formulation the task is not resolved in general because of large scale, diversity of components and non-linearity of their interactions that demands a new approach.

\section{Method: Causal-and-effect Approach to Increase Efficiency of Complex Systems}

The most important regularity of complex system behavior is historicity or development in time $[10,11]$. These ideas are formulated in all fields of knowledge and practical activity [12]. At the same time relative simplicity and observability of cause-and-effect (causal) interactions is the reason for their particular «refusal», since for example from «the earlier» is not exactly derived «in accordance with/because of». This situation caused necessity of the following research that is done in some spheres [13].

In general, it is possible to consider that modern scientific knowledge is based on the determination of causal interactions between objects, processes, events and phenomena (further - objects). They unify visions from intuitive through scientific to philosophical permitting formal logical description at deep investigation of the functional spheres, taking into consideration origin of the events, their vicinity and development in time and provide matching of knowledge that comes from various spheres of theory and practical activity.

Every object of a system, a process realized, event as changing of state or phenomena of surroundings has its reason of origin and development that connects them with other objects. Goals as future states of a system are achieved at conditions determined by mentioned factors (condition 1). Results (effects) of causal interaction changes a system and surroundings that performs some new conditions (or condition 2). For analytical description the cause-and-effect cell operation algebra is used similar to finite-state machine one [6]. The model of the cell (general at the first level of decomposition) is as follows:

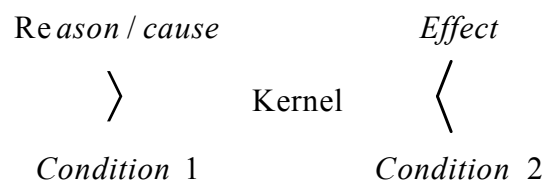

To operate with the cells some set of operations OC (oc $=1 .$. OC) is formulated:

Unification (system model creation),

Decomposition (structuring),

Intersection and Cartesian products (multi-circuit control structure),

Complements (extra- and interpolation of parameters between parts of the system with the most trustable data);

Composition (developing of the whole system model by following flowcharts of processes of known systems and models, so-called base or etalon models);

And substitution (synthesis of structures optimal on criteria).

To increase efficiency the model of an elementary causal cell structure mentioned was changed. Achieving of a simple goal by means of elementary control task solution is modeled by the elementary cause-and-effect cell. Part of the system at state SA with KPI K to achieve goals at the factors of surroundings GA under control CA by converting of resources WA is brought by means of functions and algorithms, contained in the kernel of a causal cell, to the state $\mathrm{SB}$ with conditions $\mathrm{GB}$ and control $\mathrm{CB}$ corrected accordingly to the goal achieving degree $(\|G A-G B\|)$, new $\mathrm{K}^{*}\left(\varkappa^{*} »-\right.$ after interaction) and output resources flow WB. It is possible to express $\mathrm{K}, \mathrm{G}, \mathrm{S}$ through each others. For nonelementary cases some cause-and-effect (or reasone-andconsequence, RC) complexes are created for the part or whole of the system. Casual components interact accordingly to the flowcharts of base models using operations of OC set.

There fore new model of RC-cell on the first level of decomposition at matrix view is presented, where $A$ - before and $B$ - after interaction:

$$
\left(\begin{array}{ccc}
K, C A & & K^{*}, C B \\
& A(C A, G A, W A) & \\
S A, G A, W A & S B, G B, W B
\end{array}\right)
$$

The solution of tasks in known situation is achieved by putting general, known or theoretically and experimentally proved RC-cells, its components decomposition till the level understandable by decision-makers using base models, practice performance checking, necessary feedback and correction.

If there are unknown situations or in case when there is no enough information about the system, surroundings and their interaction some parts with the most trustable data are determined. For them procedures mentioned to known situations are realized, general RC-models of the whole system are developed and optimization tasks are resolved considering known models with accuracy of data available. Results are step-by-step improved while the system is developed and/or one gets new data. Information about results put in some Petrol Data-Base (PDB). Since there are no restrictions on types of functions and algorithms of kernels, it is possible to describe interactions of objects of different nature.

\section{Results (Algorithms and Diagrams) to Improve Service Station Net}

Optimal control parameters task causal formulation is shown as folows: 


$$
\left(\begin{array}{ccc}
K_{\text {Station }} \uparrow & & G^{*} \\
& A\left(K_{\text {Station }}, G, \text { int }\right) & \\
G, n_{\text {inp }}, \alpha, \text { int } & & n_{\text {out }}
\end{array}\right)
$$

where $n_{\text {inp }}$ - input transport flow, $n_{\text {out }}-$ outpuit flow, $G_{u v} \in G$ - factors of the system and surroundings $(u=1$.. $U$ - type, $\mathrm{v}=1 . . \mathrm{V}-\mathrm{kind}$ ), int - quasi-stationary time intervals, where linear dependence or constancy are adequate and possible, $\alpha$
- statistical significance, $\mathrm{K}_{\text {station }}$ - efficiency indicator to be increased, $\mathrm{K}_{\text {station }} \uparrow$.

Generalized algorithm to determine efficient parameters of gas stations at given factors of surroundings is presented on Figure 1, where $\mathrm{R}$ - factors/parameter space, $\mathrm{R} *$-feasible region, $\mathrm{X}$ and $\mathrm{Y}$ - data of comparable objects, av -average, $\Delta \mathrm{K}$ - error. «End» operator is dotted since the algorithm is cycled due to necessity of step-by-step improvement of the system.

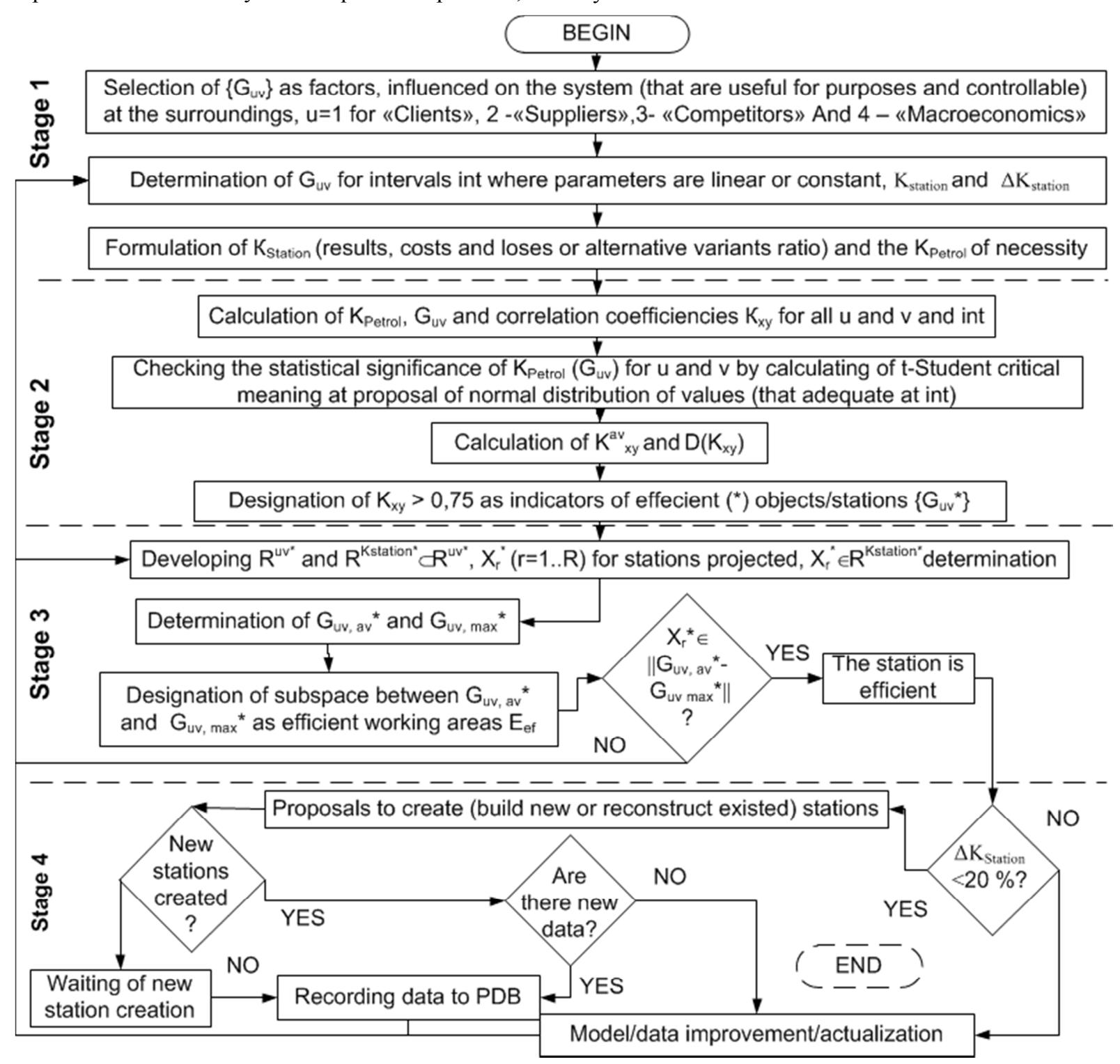

Figure 1. Generalized algorithm to determine parameters of efficient service systems.

The task to synthesize the structure of complex multicircuit systems, optimal on $K_{\text {petrol }}$ at given $G$, where $K_{\text {petrol }}$ is brought to MAX by development of structures and selecting of control actions at causal formulation is as follows:

$$
\left(\begin{array}{ccc}
K_{\text {petrol }} \rightarrow \max & X^{*}, U^{*}, K^{*}{ }_{\text {petrol }} \\
& A(C, H, P, X, U) & \\
G, C, H, P, X, U, w & G^{*}, w^{*}, G R, G R_{1}-G R_{4}^{*}
\end{array}\right)
$$

where $\mathrm{w}_{1 . .6}$ - resources $(1-$ staff, 2 - technology, 3 - energy, 4 - knowledge, 5 - finances, 6 - materials), $\mathrm{P}$ - set of processes, GR, $\mathrm{GR}_{1}-\mathrm{GR}_{4}-$ structure graphs of, correspondingly, infra-system (non-active and needed control), control (1), decision making (2), organizationtechnical (3) and information (4) systems. It is supposed [14] that the models are enough to describe a whole system. A system structure is synthesized accordingly to the following informational logic diagram presented in written form.

On the I-st stage there is an analysis of system at 
surrounding conditions.

a) Designation and specification the goals as components of the $\mathbf{X}$ vector given by decision-makers. It depends on factors of surroundings $\mathrm{G}$, flow chart of processes $\mathrm{S}$, control means characteristics $\mathrm{X}$ and relations between them U, i.e. $\mathbf{X}(\mathrm{G}, \mathrm{S}, \mathrm{X}, \mathrm{U})$. Quantitively they are determined by data of real working objects.

b) Specifying the system in surrondings adding to it some controllable components data of which descisionmakers can evaluate goals achievability.

c) Determination of boundaries between controllable and control systems accordingly to activity (deliberate changing of information) of components. Non-active or infra-system does not have the property and needed control.

d) Determination the factors of Consumers, Suppliers, Competitors, Macro-economics, upper- and lower-level systems and so on as $\mathrm{G}$ components.

e) Designation $K_{\text {Petrol }}=\frac{R_{\text {Petrol }}-L_{\text {Petrol }}}{C_{\text {Petrol }}}$ as KPI, where $\mathrm{R}_{\text {Petrol }}-$ results, $\mathrm{C}_{\text {Petrol }}-$ costs, $\mathrm{L}_{\text {Petrol }}-$ loses (outages, untrained staff, etc.), and $\Delta \mathrm{K}_{\text {Petrol }}$ possible.

f) Formation of parameter space and efficient working areas $\mathrm{E}_{\mathrm{ef}}$ (see Figure 1).

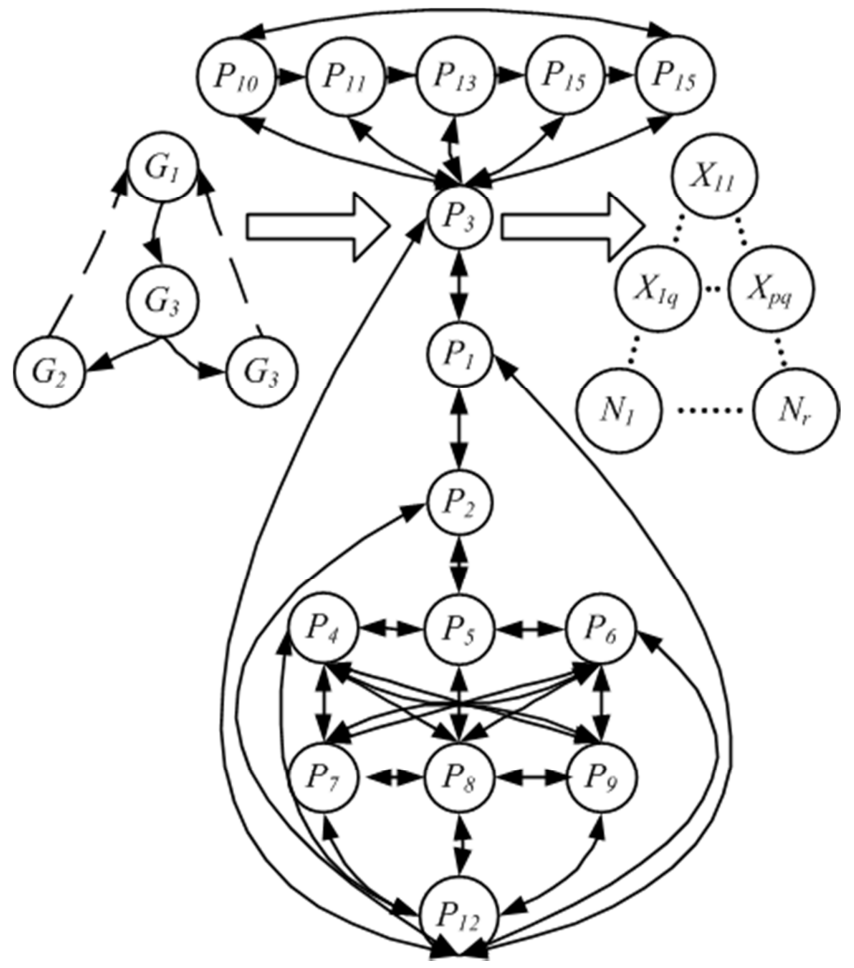

Figure 2. Typical relations between goals, processes and objects in gas station nets.

On the II-nd stage the structure of control system is formed.

a) Formation of the process flow charts and object structures accordingly to the known models that are acumulated in PDB.

b) Determination of permitted dominative and sequence relations between objects $\mathrm{N}$, processes $\mathrm{P}$ and goals $\mathrm{G}$ using results of the sphere analisis [15] done (Figure 2). On Figure $2 \mathrm{P}_{1}-$ petroleum product supply, $\mathrm{P}_{2}-$

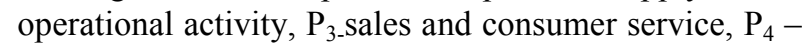
accounting and reporting, $\mathrm{P}_{5}-$ maintenance and repairing, $\mathrm{P}_{6}-$ staff training, $\mathrm{P}_{7}-$ security, $\mathrm{P}_{8}-$ energy provision, $\mathrm{P}_{9}-$ transport, $\mathrm{P}_{10}-$ information service, $\mathrm{P}_{11}$ -purpose-oriented direction, $\mathrm{P}_{12}$ - procurement, $\mathrm{P}_{13}-$ analysis, $\mathrm{P}_{14}-$ decision making, $\mathrm{P}_{15}-$ control; $\mathrm{X}_{\mathrm{pq}}-$ control means $(\mathrm{p}=1 . . \mathrm{P}-$ type, $\mathrm{q}=1 . . \mathrm{Q}-$ level $) ; \mathrm{N}_{1 . .} \mathrm{r}-$ infra-system objects non-active at the view.

c) Formation of controllable system structure as interconnected recource-converting objects accordingly to the processes structure of Figure 2.

On III-rd stage control system structure is formed.

a) Specifing the control time periods $\mathrm{H}_{\mathrm{k}}(\mathrm{k}=1 . . \mathrm{K})$, control functions $\mathrm{C}_{\mathrm{i}}(\mathrm{i}=1 . . \mathrm{I})$ and control means $\mathrm{X}_{\mathrm{pq}}$ accordingly to the models of PDB mentioned.

b) Forming sets of elementary control tasks $F_{i j \mathrm{kpq}}: C_{i} \times$ $P_{j} \times H_{k} \times X_{p q} \quad$ and circuits $F C_{j k p q}: C_{1 . .5} \times P_{j} \times H_{k} \times X_{p q} \quad$ where $\langle\mathrm{x} »$ means Cartesian products.

c) Control system structure model creation or $\Omega$-synthesis and refusal circuits with the low efficiency, w/o necessary automation level or meaningless.

On the IV-th stage there is a synthesis of control system structure by circuits convolutions. Some better $X_{p q}$ may be added and convolutions are done until limits of their properties, considering efficiency and level of automation.

a) C-convolution (synthesis) as integration of control functions alongside control circuits and designation more $C_{i}$ to the smaller number of $X_{p q}$.

b) P-convolution as an integration of control functions belonging to various control circuits of processes $P_{j}$ by designating of more $\mathrm{C}_{\mathrm{i}}$ to be performed by the same $\mathrm{X}_{\mathrm{pq}}$.

c) H-convolution as an integration of control functions $C_{i}$ on various time periods by lower number of $\mathrm{X}_{\mathrm{pq}}$.

On the V-th stage one looks optimal variants of the system structure.

d) Forming of control circuit set ( $\Omega$ 'synthesized) and determination of KPetrol.

e) Designation as optimal those structures, KPI of which are closest to Eef. If it is not achieved, one goes to Stage I.

f) Forming of organization-and-technical system structures by bringing new and/or improving existing control means accordingly to the control system structure (see p. 5.2) and requirements to control means Xpq.

g) Forming the information system structure by putting data arrays and transmission channels to control and organizational-technical system structures already done (see pp. 5.2 and 5.3).

h) Forming the decision-making structure by designation to the components of organization-and-technical system 
structures and the same for information system types of decision-making acts using PDB mentioned [15].

i) Proposal to improve the model and algorithm, transition to Stage II.
The task to form structures and choose optimal control actions for service nets using system cause-and-effect approach is resolved by the following informational logic diagram (Figure 3).

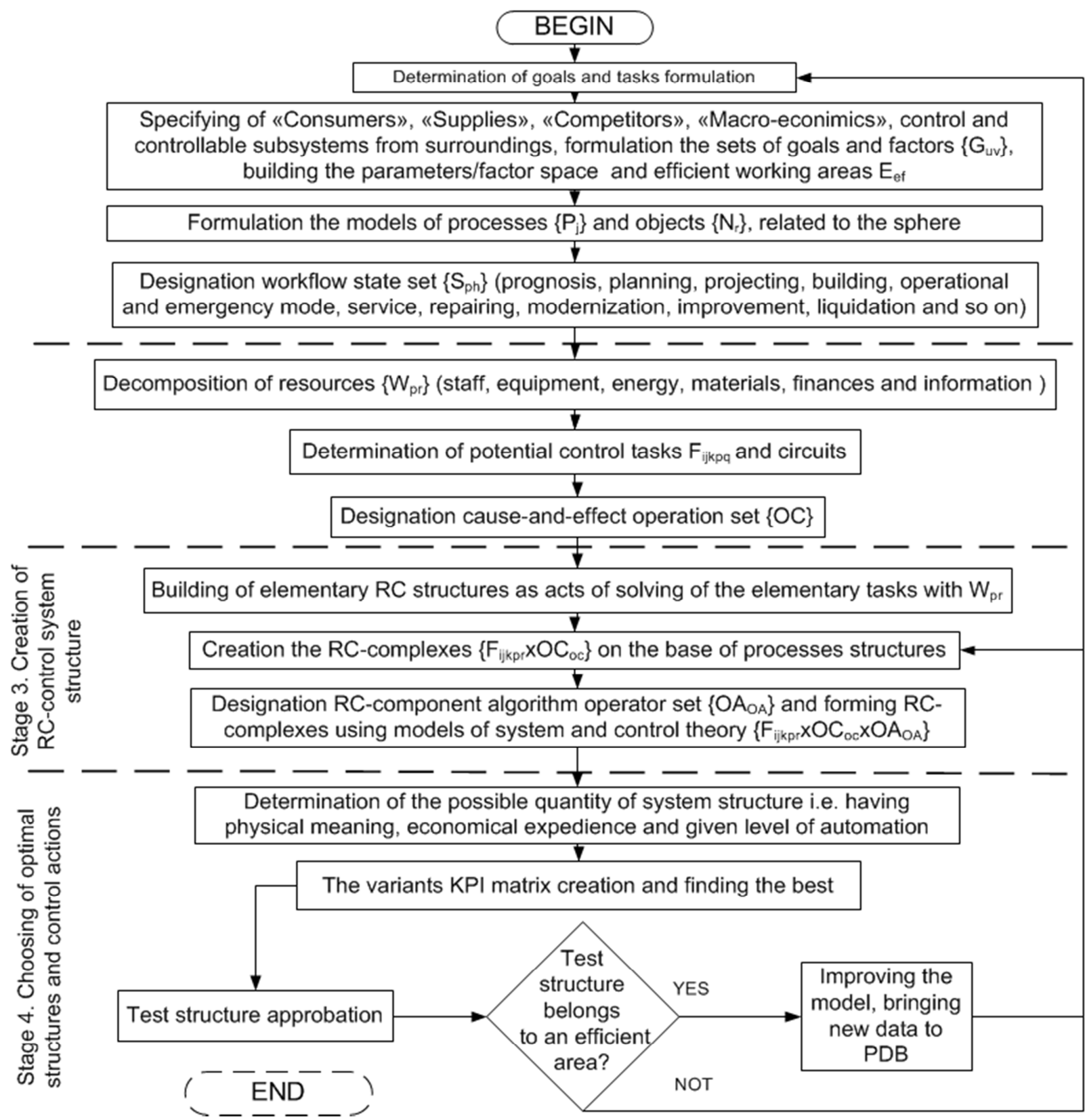

Figure 3. Information-logic diagram to form structure and choose control actions for service (gas) nets, optimal on the given criteria with using system reason-and effect approach.

\section{Discussion}

As a result of the causal approach application proposed it was developed the complex of inter-related informational logic diagrams and algorithms to impove service nets as a part of the methodology of rational development and continious improvement of service station nets and effecient automatical control of processes and objects in the systems (Methodology). Basic components of the methodology are presented on Figure 4.
On the base of the Methodology there were solved some practically important tasks [15].

In particular, there were found optimal gas station parameters at various types of street-and-road nets. It was shown that as optimal on the criterion of minimum outage of clients and service channels may be considered (if one minds fuel sales only) the structure of two dispensers with all of the fuels being sold on the station. Outdoor payment terminals built in dispencers provide at least $10 \%$ higher productivity. During 2000-2014 the model was applied on more than 150 
objects.

For gas station nets it was proved that up to $80 \%$ of the modern and perspective flows of clients may be served by smaller quantity of stations. For various types of street-androad nets there were found some characteristics (quantity of cross-roads, distances between neighboring stations and their quantity), providing minimal redistribution of clients bertween objects of the same net for small (up to 500 thousand residents) and medium (up to 1,5 million residents) cities and towns for non-dominating petroleum supply company, operating smaller that $25 \%$ of a region stations, and the same on highways.

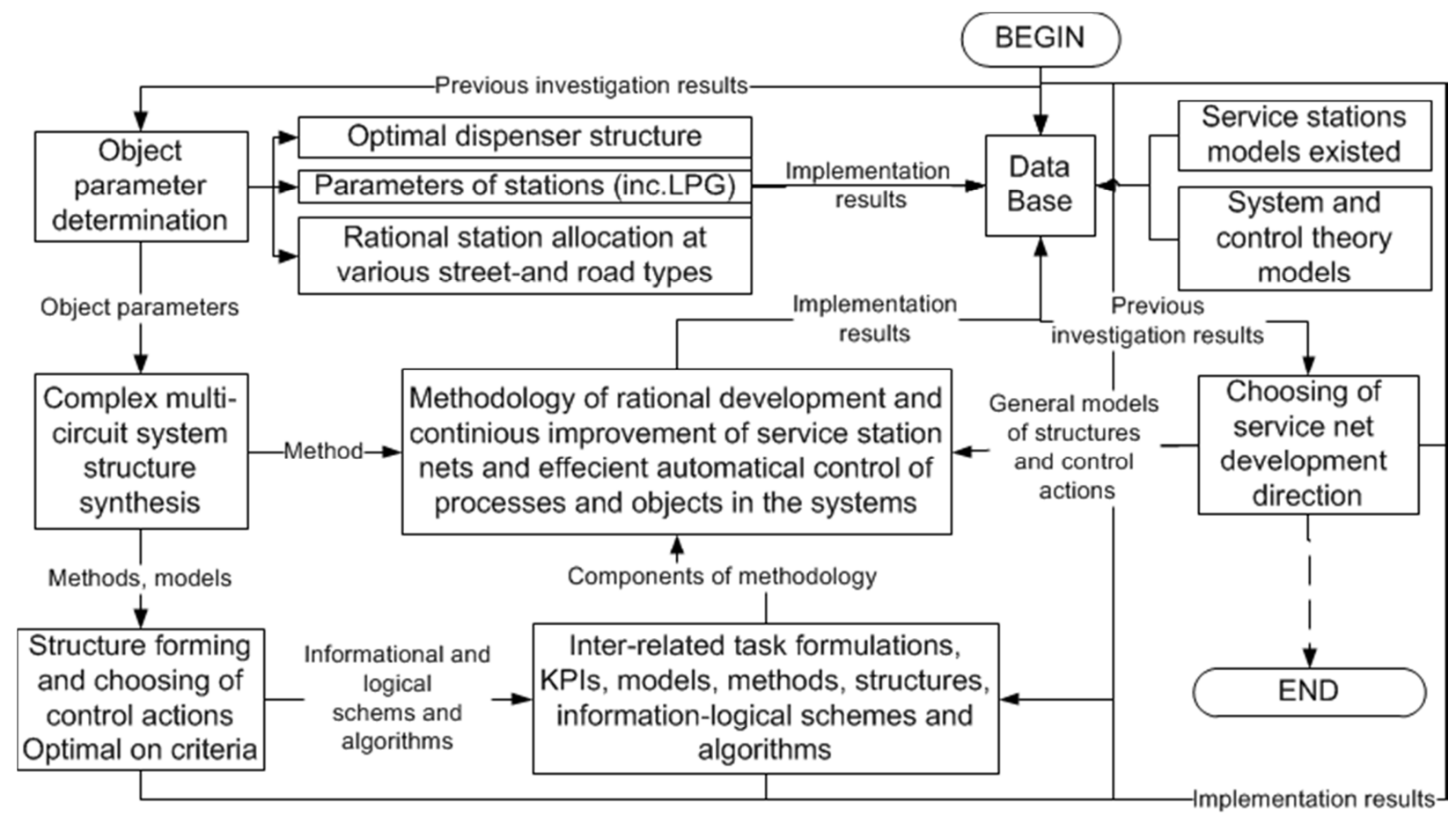

Figure 4. Interaction of information-logic diagrams and algorithms to improve service nets.

Also in some regions of middle Russia there were developed optimal structures to serve card clients that increased sales in volume in 6 times. In these regions and some CIS countries there were changed technical maintanance systems that provided cost reduction in 3-15\% at better service. Moreover there were prepared efficient system structures to serve clients near pumps, security, automation, procrurement counter-actions, capital construction, etc. Finally, it was done modelling of processes on stations that permitted to increase staff training skills in newly built trainng centers in Saratov and Volgograd-cities.

\section{Conclusion}

Service nets are important for an economy and require their continuous improvement.

A causal-and-effect approach was suggested and new informational logic diagrams and algorithms were developed. They are characterized by co-synthesis of controllable and control systems, descision-making in case of not enough trustable data from systems and surroundings, possibility to match objects, processes, events and phenomena of various nature and so on.

Adequatnes of the methodology is cofirmed by the proximity of the known and developed models on the similar feasible regions, reliability of results by statistical data for more than 15 years of observation, validity of conclusions by results of approbation and successful multiple applications. Said above permits to use it for other service nets and complex system at all.

\section{Conflict of Interest Statement}

All the authors do not have any possible conflicts of interest.

\section{Acknowledgements}

I can say as much thanks as possible to my scientific adviser and teacher Alexandr F. Rezchikov (correspondentmember of Russian Academy of Sciences) and my First General Director Semen M. Glozman for all of the so good things that they have done for me.

\section{References}

[1] McConnell, Campbell R. Economics: principles, problems, and policies / Campbell R. McConnell, Stanley L. Brue, Sean M. Flynn. - The McGraw-Hill series in economics 18th ed$917 \mathrm{p}$.

[2] Dyke K. V. Fundamentals of Petroleum. - Austin (Texas): Petroleum Extension Service, 1997. - 360 p. 
[3] Davletiyarov F. A. Petroleum Supply / F. A. Davletiyarov, E. I. Zorja, D. V. Zagarelli. - М.: ИЦ «Matematika», 1998. - 662 p. (In Rus).

[4] Berman O. Optimal Location of Discretionary Service Facilities / Oded Berman, Richard C. Larson, Nikoletta Fouska // Transportation Science. - V. 26. - Aug. 1992. - P. 201-211.

[5] Hakimi S. L. Optimal Locations of Switching Centers and the Absolute Centers and Medians of Graph / S. L. Hakimi // Opns. Res. - 1964. - P. 450-459.

[6] Bezrodniy A. A. Structure models and control algorithms of gas stations / A. A. Bezrodniy, A. F. Rezchikov. - Saratov State Technical University, 2004. - 249 p. (In Rus).

[7] Drucker P. F. Management Challenges for the 21-st century / Peter F. Drucker. - New York: HarperCollins Publishers Inc., 2002. $-207 \mathrm{p}$.

[8] Korolenok A. M., Fundamentals of hydrocarbons and commercial petroleum products resource-saving at the stages of storage, wholesale and retail / Zorya E. I., Korolenok A. M., Loshchenkova O. V., Kitaschov Y. N. - M.: MaxPress, 2018.-640 p. (In Rus).
[9] Buslenko N. B. Complex system modelling / N. B. BuslenkoM.: Nauka, 1968. - 342 p. (In Rus).

[10] System analysis and descision-making / under the guidence of V. N. Volkova. - M.: Vicshaya Schkola, 2004. - 616 p. (In Rus).

[11] Forrester. J. Principles of systems. - Cambridge: Wright Allen Press, 1960.

[12] Ishikawa K. Guide to Quality Control / K. Ishikawa. - Tokyo, Asian Productivity Organization, 1976.

[13] Rezchikov, A. The Approach to Provide and Support the Aviation Transportation System Safety Based on Automation Models / A. Rezchikov, V. Kushnikov, V. Ivaschenko, A. Bogomolov, L. Filimonyuk, O. Dolinina, E. Kulakova, K. Kachur // Advances in Intelligent Systems and Computing, Springer International Publishing. - 2017. - Vol. 575. - P. 244-254.

[14] Tsvirkun A. D. Structure of complex systems. - M.: Nauka, 1981. - 345 p. (In Rus).

[15] Bezrodniy A. A. Systematical cause-and-effect approach to control petroleum supply. - Saarbrucken. Lambert Academic Publishing, 2017. 319 p. (In Rus).

\section{Biography}

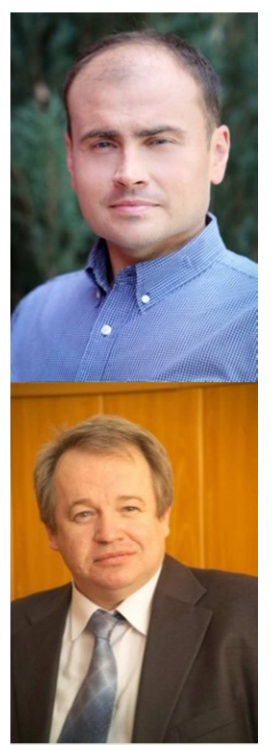

Alexey Anatolievitch Bezrodny. He graduated from Saratov State University (Physics) in 1995 and RANEPA (Civil service) in 1999 and participated in the Yeltsin Democracy Fellowship Program (in-Canada training) in 2001-02. In 1995-97 Mr. Bezrodniy worked in Volga R@D Institute in the Field Emission Display Team with SAMSUNG (Korea). From 1997 he has been working for LUKOIL in Russia, Turkey and Ukraine in engineering, automation, construction, etc of petroleum supply. He became a candidate of sciences in mathematical modeling in 2004 and a Doctor of Sciences in System analysis and control in 2011. Since 2015 he works in the LUKOIL central office (Moscow) being professor at the Gubkin university.

Anatoliy Mikchailovitch Korolenok. In 1977 he graduated from the Bauman Moscow State Technical University, where he worked as a trainee-investigator. In 1981 he became a candidate of sciences in petroleum engineering and worked as a senior engineer, researcher and professor at the Gubkin university. Mr. Korolenok became a doctor of sciences in 1999, from 2003 he is the Dean of the Faculty of Design, Construction and Exploitation of Pipeline transport systems. Anatoliy M. Korolenok trained 12 candidates and 2 doctors of sciences, he is the author of 130+ articles and books, member of five scientific journal editorial boards, three thesis councils (a chairman in one) and two technical ones. He is an honorary worker of Russia petroleum and High professional education spheres and Russian government prize winner in education.

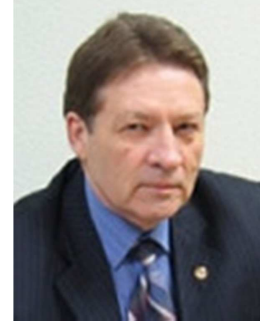

Aleksandr Fedorovitch Rezchikov. In 1977 he graduated from the Samara industrial institute (automation). In 1961$64 \mathrm{Mr}$. Rezchikov worked in a factory in Saratov-city, in 1967 he post graduated Saratov Polytechnic Institute, where continued as a researcher, professor and chief of a Department. In 1968 he became a candidate of sciences in electromechanics, in 1987 - a doctor of sciences defended his thesis in the V.A. Trapeznikov Institute of Control Sciences (ICS), in 2003 - was elected as a correspondent-member of the Russian Academy of Sciences. During 1970-80-s Aleksandr A. Rezchikov was scientific secretary of Volga region committee of USSR Academy of Sciences and Chief of Economics Department of Saratov region political administration. In 1987 he became director of the Institute of Precision Mechanics and Control of the USSR Academy of Sciences whom he was till 2016 when he continued his activity in ICS in Moscow. Mr. Rezchikov created the scientific school of complex system control, trained 21 candidates and 6 doctors of sciences, the author $200+$ articles and books, member of three scientific journal editorial boards, a honorary worker of science of Russian Federation, etc. 